\title{
Technological Features and Effectiveness of Human Resource Information System in Tanzanian Local Government Authorities
}

\author{
Hadija Matimbwa ${ }^{1, *}$, Orest Sebastian Masue $^{2}$, Venance Shilingi ${ }^{2}$ \\ ${ }^{1}$ Department of Management Science and Procurement, Faculty of Business and Management Science, Ruaha Catholic University, Iringa, \\ Tanzania \\ ${ }^{2}$ Department of Public Service and Human Resource Management, School of Public Administration, Mzumbe University, Morogoro, Tanzania \\ Email address: \\ hadija.matimbwa@gmail.com(H. Matimbwa), orest.masue@mzumbe.ac.tz(O.S. Masue), vshillingi@mzumbe.ac.tz(V.Shillingi) \\ ${ }^{*}$ Corresponding author
}

\section{To cite this article:}

Hadija Matimbwa, Orest Sebastian Masue, Venance Shilingi. Technological Features and Effectiveness of Human Resource Information System in Tanzanian Local Government Authorities. American Journal of Operations Management and Information Systems.

Vol. 5, No. 3, 2020, pp. 29-40. doi: 10.11648/j.ajomis.20200503.11

Received: August 5, 2020; Accepted: August 22, 2020; Published: September 8, 2020

\begin{abstract}
Information and Communication Technology has drastically become indispensable for companies aiming to favourably compete in the business world. The traditional way of storing information is losing its ground; organisations are abandoning paper documents and quickly adopting digital storage. Today, most organizations have upgraded their file storage systems from paper filing to digital filing whereby documents are stored on servers and storage devices. By so doing, documents can be easily accessed by anyone who is granted access. Organizations are able to store and maintain tremendous amount of information, which enhance immediate access of information from the system. Tanzania like many other countries has decided to use Human Resources Information System (HRIS) to replace manual record systems in Ministries Departments and Agencies (MDAs) and the Local Government Authorities (LGAs). The aim of introducing HRIS in the MDAs and LGAs was to reduce manual performance of administrative activities and to enable HR officers maintain complete, accurate and up-to-date employees' information by using computerized application software. The purpose of this article is to assess the influence of technological features on (HRIS) effectiveness. The study involved 37 LGAs in six regions-Mwanza, Arusha, Dodoma, Morogoro, Iringa, and Kagera. Primary data were collected through administration of 201 questionnaires to Human Resource Officers (HROs) and interviews with 8 key informants. Secondary data were mainly collected through documentary review. Data were analysed using both descriptive and inferential statistics. The study employed the ordered logistic regression model to assess the influence of technology features on the effectiveness of HRIS in LGAs in terms of information timeliness, completeness and accuracy. Based on the results, technological features have significant influence on HRIS effectiveness in terms of timeliness, completeness, and accuracy of information. These include compatibility, complexity, usefulness and reliability. The implication of the results is that a new and reliable system is needed to facilitate decision making, increase access from other devices, address the needs of the institution, and be procedurally clear. It was suggested that the current system should be changed to accommodate technological advancement and cover loopholes which are being manipulated by employees in LGAs.
\end{abstract}

Keywords: Effectiveness, Human Resource Information System, Technological Features \& Local Government Authority

\section{Introduction}

The human resources (HR) department is one of the most important departments of any organization regardless of whether the organization is public or private, profit or non-profit, and whether it produces goods or provide services. Of all its responsibilities, the department is tasked to keep and update personnel records, including recruitment and selection, employee reports, deductions, career planning, training and development $[14,31]$. Given its importance, there has been an investment in finding an efficient and effective system to simplify operations and increase productivity. This is caused by the fact that for many 
years, all personnel records were documented in paper form (paper based system), which was much slower, untimely, and inaccurate in output production $[16,23]$. The paper based system made it difficult to integrate employee information from various departments within organizations (e.g. HR department and finance department) and consequently, employers wasted a lot of money on ghost workers.

Technological advancement has led to the emergence of a modern information-processing system known as the Human Resource Information System (HRIS). The system has two main parts; 1) Human Resource (HR), and 2) Information and Communication Technology (ICT) application [22]. Collectively, the system is responsible for an immense revolution in the HR department including hastening of employee information, improving intra and inters departmental coordination and information sharing, facilitating access to information, reduction of operational costs etc. These benefits were lacking in the past when the paper based system was used in HR department [1, 2, 3, 36]. Out of the two parts of the HRIS, ICT application is largely based on the availability of ICT equipments and knowledge and skills. The presence of both equipments and skills are essential for the system to provide quality information.

In Tanzania, many organizations have been using the system to keep employees records. These include government Ministries, Departments and Agencies (MDAs), Local Government Authorities (LGAs), corporations, private companies, and non-governmental organizations. In relation with the government, the use of the system began in 2011 in central government, and a few years later, the system was introduced in LGAs. Since the use of the system is largely based on availability of technological equipments and ICT skills, the government has put a lot of efforts in purchasing equipments and facilitating ICT training for HR officers in LGAs. The aim was to eliminate the challenges that arose from the use of the paper based system. To-date, the system is used in all LGAs. Unfortunately, the application of the system in LGAs has resulted into incomplete, inaccurate and outdated civil servants' information as demonstrated by the high number of ghost workers, inefficient recruitment, and payroll fraud [18, 24].

Publications on HRIS have recently increased. Most studies have focused on various aspects of the HRIS, including the use of the system and its adoption, the benefits of using the system and its challenges, and the factors that determine an institution's decision to use the system [2, 5, 9, 21]. However, most of the studies have been conducted outside Tanzania. In Tanzania, such studies are limited; those available are mainly focused on the use and adoption of the system [18, 19, 24]. No or limited studies have been conducted to assess the influence of technological features on HRIS effectiveness. Such studies are particularly relevant in light of recent government reports that highlighted the existence of various challenges in the public service sector emanating from the use of HRIS. Many of these challenges were identified in LGAs. Thus, this study aims to provide answers to how technological features lead to HRIS effectiveness. In particular, the study aimed to find answers to the following questions on the use of the system in LGAs in Tanzania.
(Question 1): What is the relationship between technological features and HRIS effectiveness in LGAs in Tanzania?

(Question 2): What is the extent of influence of technological features on HRIS effectiveness in LGAs in Tanzania?

The two questions aimed to explain the influence of technological features on effectiveness of the HRIS in LGAs in Tanzania. This is due to the fact that the topic has received no or little attention by HRIS scholars in Tanzania. As pointed out earlier, the majority of previous studies in Tanzania focused on adoption, uses, and benefits of the system. Elsewhere, especially in developed countries where technology is well advanced, scholars have pointed out that technological features play a great role in augmenting the performance of the system $[18,19,24]$. Such information is lacking in Tanzania, particularly in LGAs. Therefore, the first question majors in the relationship between technological features and effectiveness of HRIS. Effectiveness is assessed based on information timeliness, information completeness, and information accuracy. The answer to the $1^{\text {st }}$ question will reveal whether a relationship between technological features and HRIS effectiveness exists and will equally seek to establish its strength and if is statistically significant. $2^{\text {nd }}$ question seeks to explore the influence of technological features on HRIS effectiveness i.e. modeling the relationship in order to understand which technological features namely compatibility, complexity, reliability, and usefulness have more influence on HRIS effectiveness.

The empirical context of our study is LGAs in Tanzania, which are public administration bodies that are placed at the lowest tier of administration [28]. The establishment of LGAs in Tanzania dated back during the colonial period when the British administration in Tanganyika introduced LGAs (native authorities). After independence, the government sustained LGAs until 1972 when they were abolished in order to pave way for the introduction of the Regional Decentralization (decentralization by deconcentrating). LGAs were re-established by Act No. 7-10 of 1982 to enhance the decentralization process by devolution ( $\mathrm{D}$ by $\mathrm{D})$. To-date, objectives of local governments in Tanzania is governed by Article 145 of the Constitution of the United Republic of Tanzania of 1977 [28] One of the objectives is to transfer the authority over planning and implementation of development programmes to the people (Ibid).

\section{Theoretical Background Information of the HRIS}

There are several conceptual views on the meaning of HRIS. However, all definitions describe HRIS as a software or online solution for data entry, data tracking, and information needs of the human resources, management, and accounting functions within an organization $[12,13]$. The system is necessary for employee management, knowledge development, career growth and development, and facilitating equal treatment [17, 34]. Through the system, HR managers in an organization can access the information they need to legally, ethically and 
effectively support the success of reporting employees [26].

As described earlier, HRIS has two main components: 1) Human Resource Management (HRM), particularly its basic HR roles and processes, and 2) ICT use [24]. This study focused on the second component, which is ICT use. This is due to the fact that, ICT is grounded in technology. It is urged by several scholars that for the system to operate optimally, it requires installation of relevant hardware (e.g. desktop PCs for accessing and inputting information locally, Uninterruptible Power Supply-UPS, Printers), software and support components (e.g. Server-side software such as HTML, Java, Perl; Intranet communications protocol; Relational database/Information processing software for records, payroll) [39]. In addition, it requires reliable internet to easily send and receive information between departments and yet almost all LGAs are connected with National Information Technology Backborne (NICTBB) Optic Fibre Cable [37].

To discuss the influence of technological features have on HRIS effectiveness; this study employs Unified Theory of Acceptance and Use of Technology (UTAUT) [7, 38]. The theory has been used in various studies to investigate users' technology acceptance [2, 20, 35]. Many studies have shown that the usefulness of technology and ease of use are the main factors affecting an individual's technology acceptance [10]. The UTAUT integrates the proper process of adopting and implementing HRIS in LGAs for improved output that is complete, accurate, and up-to-date. It is also used in this study to develop variables for measuring the influence of technological features (Compatibility, Complexity, Reliability and Usefulness) on HRIS effectiveness (completeness, timeliness and accuracy) in LGAs in Tanzania.

\section{Research Methods}

\subsection{Study Areas}

The study was conducted in six regions in Tanzania Mainland namely Mwanza, Arusha, Dodoma, Morogoro, Iringa, and Kagera. Sampled regions represent different levels of ghost workers as reported in the Civil Servants' Auditing Report of 2016 [37]. The selection of regions was proceeded by stratification of regions based on the number of ghost workers reported. Three strata were created; high ( $>150$ ghost workers), moderate $(<150$ but $>50$ ghost workers), and low $(<50$ ghost workers). Regions in each stratum were first assigned a unique identification number and in each stratum, two regions were randomly selected for further assessment of influence of technological features' on HRIS effectiveness. In each stratum, the random between functions in MS excel was used to pick two regions randomly. According to the Civil Servants' Auditing Report, Mwanza had 334 and Arusha had 270 ghost workers [37] Mwanza ultimately represented 5 regions with high numbers of ghost workers. Dodoma had 139 and Morogoro had 122 ghost workers [37], Dodoma thus, represented 9 regions with a moderate number of ghost workers. Iringa had 15 and Kagera had 14 ghost workers [37] Iringa represented 9 regions with few ghost workers. In addition to the ghost workers, the audit discovered 9,932 civil servants with forged certificates [25, 30, 40]. The audit particularly revealed that more than 1500 academic credentials were used by multiple employees while 11,500 civil servants had incomplete records $[4,40]$. Among the 9,932 public servants with forged certificates, 87.76 percent (8716) were from the LGAs in the selected Regions and the remaining 12.24 percent (1216) were from the central government [40].

\subsection{Data Collection Methods}

Field work was conducted in two sequential distinct phases of quantitative and qualitative data collection. The first phase started with quantitative data collection and analysis of the numerical data relevant to the research questions. The second phase was then conducted mainly for collection of qualitative data. Quantitative data were collected through a structured questionnaire administered to Human Resources Officers (HROs).

HROs were chosen because are well informed and possess valuable knowledge on the application and effectiveness of the HRIS in LGAs as they consistently use HRIS. The sampling frame for the study comprised all HROs in the selected regions amounting to 249 HROs. The sample size was 213 HROs, which was obtained by employing a formula developed by Robert and Morgan, [6, 31]. Out of 213 respondents, the researcher managed to get 201 respondents, which was a sufficient sample size $[8,11,27]$.

In each region, all district councils (i.e. Local Government Authorities-LGAs) were selected to obtain data for the study. To obtain the number of HROs for questionnaire survey per district council, proportional sampling was used (Equation 1). In each district, HROs who participated in the questionnaire survey were randomly picked using MS Excel. Respondents were asked questions and their responses were recorded on the questionnaires against the question asked. The researcher was helped by two research assistants in order to quicken and facilitate the data collection process. The research assistants were recruited based on their familiarity with ICT and HR practices not only to simplify the training process but also to ensure accurate data collection. The training focused on HR practices, enumerators' roles, questionnaire administration, data recording, data collection methods, and adherence to research codes of conduct and ethics.

$$
S_{d}=\left(\frac{H R O_{d}}{H R O_{T}}\right) \times G_{s}
$$

Where:

$\mathrm{S}_{\mathrm{d}}=$ sample per district (i.e. number HROs sampled per district/LGAs)

$\mathrm{HRO}_{\mathrm{d}}=$ number of HROs available in the district/LGA that was used to prepare sampling frame

$\mathrm{HRO}_{\mathrm{T}}=$ total number of HROs in all sampled regions (i.e. all LGAs in sampled regions) $=249$ HROs

$\mathrm{G}_{\mathrm{s}}=$ General sample size obtained using a formula developed by Robert and Morgan [6] = 213 HROs

Qualitative data were collected through in-depth interviews with key informants selected based on their HRIS knowledge. 
These included HROs (approvers) and Directors of Human Capital Division. A total of six (6) HROs ("approvers") and two (2) Directors of Human Capital Division were approached and interviewed. To supplement primary data, secondary data were collected by reviewing and analysing various relevant documents such as ICT policies, HRIS reports on diverse issues accessed from government authorities such as recruitment and promotion procedures, ghost workers, and counterfeit certificate reports.

\subsection{Data Analysis Methods}

Data collected through structured questionnaires were summarized, coded, and entered into the IBM-Statistical Package for Social Sciences (SPSS) computer programme version 21.0 for analysis. Respondents' preliminary information was analysed using descriptive statistics; frequency and cross tabulation in particular. To examine the influence of technological features on HRIS effectiveness, the study employed the ordered logistic regression model. Technological features comprise compatibility, complexity, reliability, and usefulness. In building the model, technological features were treated as variables predictor where by effectiveness in terms of timeliness, completeness, and accuracy were dependent variables; one model for every dependent variable was employed. Equation 2 presents the model specifications as follows:

$$
\operatorname{Pr} o b(Y)=\beta_{0}+\beta_{i j} X_{i j}+\ldots+\beta_{n} X_{n}+\varepsilon
$$

Where:

$\mathrm{Y}=$ HRIS effectiveness in LGAs (ordered to be measured by Five Point Likert Scale of timeliness of information, Completeness of information and Accuracy of information).

$\beta 0=$ Constant term

$\beta \mathrm{ij}-\beta \mathrm{nj}=$ Explanatory indicators (coefficient estimates) of predictor ' $\mathrm{i}$ ' to ' $\mathrm{n}$ ' in setting $\mathrm{j}$

$\mathrm{Xij}-\mathrm{Xij}=$ Predictor ' $\mathrm{i}$ ' to ' $\mathrm{n}$ ' of $\mathrm{Y}$ in setting $\mathrm{j}$ in this study, predictors are technological features,

$\varepsilon=$ Normally Distributed Error Term

The dependent variable was categorically measured through a five-point Likert scale and responses were ranked as 1= Strongly Disagree; $2=$ Disagree; $3=$ Neither Agree nor Disagree; $4=$ Agree; 5 $=$ Strongly Agree. Technological features were recorded as either numerical (discrete and continuous) or categorical variables.

The modelling procedure started by checking multicollinearity of technological features. Multicollinearity exists whenever an independent variable is highly correlated with one or more independent variables; for this case the cut point was $r=0.9$ and above [32]. The results of correlation matrix (which is not presented here due to space limitations) show that the maximum $r$ $=0.444$; thus, no variable was excluded i.e. all variables were included in the modelling procedure.

Qualitative data were subjected to content analysis. Content analysis helps to reduce the volume of recorded information or communication to a set of categories that represent some features of the research. The content analysis was conducted to produce information that could explain the situation in the field regarding HRIS effectiveness in improving employees' information in the selected LGAs.

\section{Results}

\subsection{General Distribution of Technological Features}

Table 1 presents a general distribution of technological features of respondents in the study areas. Generally, results show that almost half of the HROs interviewed (47.8\%) neither agreed nor disagreed with the compatibility of HRIS.

Table 1. General Distribution of Technological Features.

\begin{tabular}{|c|c|c|}
\hline Attributes & Responses & n (\%) \\
\hline \multirow{3}{*}{$\begin{array}{l}\text { Compatibility (i. e. the system can be rapidly changed or upgraded and the system can } \\
\text { be legally accessed from other devices) }\end{array}$} & Disagree & $28(13.9)$ \\
\hline & Neither agree nor disagree & $96(47.8)$ \\
\hline & Agree & $77(38.3)$ \\
\hline \multirow{2}{*}{$\begin{array}{l}\text { Complexity (i.e. the system provides clear instructions for users to operate, prepare } \\
\text { inputs, and interpret output; and the procedures provided are clear and detailed }\end{array}$} & Neither agree nor disagree & $56(27.9)$ \\
\hline & Agree & $136(67.7)$ \\
\hline \multirow{2}{*}{ Reliability (i.e. HRIS has been reliably operated in the district) } & Disagree & $35(17.4)$ \\
\hline & Agree & $83(41.3)$ \\
\hline \multirow{3}{*}{$\begin{array}{l}\text { Usefulness (i.e. the information addresses my needs and the system facilitates decision } \\
\text { making) }\end{array}$} & Disagree & $14(7)$ \\
\hline & Neither agree nor disagree & $35(17.4)$ \\
\hline & Agree & $152(75.6)$ \\
\hline
\end{tabular}

Source: Field Data (2019).

Regarding complexity, the majority $(67.7 \%)$ agreed that the system was flexible. This means that they accepted the fact that HRIS provides clear instructions for users to operate, prepare inputs and interpret output, and the procedures provided are clear and detailed. The results in table 1 further show that the respondents $(75.6 \%)$ had varied opinions on reliability of HRIS while three quarters agreed that HRIS was useful.

\subsection{Distribution of Technological Features Across Regions with High, Medium and Low Levels of HRIS Challenges}

Table 2 presents distribution of technological features across regions with high, medium, and low levels of HRIS challenges. As shown in table 2, the majority of HROs who 
agreed that the system was compatible were from regions with low levels of HRIS challenges (i.e. in low category). The responses across three categories using Chi-square test were statistically significant with $\chi^{2}=12.557$ at $p=0.014$. On the other hand, the majority of HROs who agreed that the system was complex were from regions with medium levels of challenges (i.e. in medium category). Again, responses across the three categories were statistically significant with $\chi^{2}$ $=12.206$ at $p=0.016$ Furthermore, on whether the system was reliable, the majority (62.1\%) of HROs from regions with low levels HRIS challenges (i.e. in low category) agreed that the system was reliable. The responses across the three categories were statistically significant with $\chi^{2}=15.177$ at $p=0.004$.

Regarding usefulness of the system, the results in table 2 show that the majority of HROs $(82.6 \%)$ who agreed about system reliability were from regions with medium levels of HRIS challenges (i.e. in medium category). However, differences in responses across the three categories were statistically not significant with $\chi^{2}=3.826$ at $p=0.43$ (Table 2).

Table 2. Technological Features and Levels of Challenges of HRIS.

\begin{tabular}{|c|c|c|c|c|c|c|c|}
\hline \multirow{2}{*}{\multicolumn{2}{|c|}{ Technological features }} & \multicolumn{3}{|c|}{ Level of Challenges of HRIS } & \multirow{3}{*}{$\begin{array}{l}\text { Total } \\
28(13.9 \%)\end{array}$} & \multirow{3}{*}{$\begin{array}{l}\text { Chi-square } \\
12.557\end{array}$} & \multirow{3}{*}{$\begin{array}{l}\text { p-value } \\
.014\end{array}$} \\
\hline & & \multirow{2}{*}{$\begin{array}{l}\text { High } \\
13(17.6 \%)\end{array}$} & \multirow{2}{*}{$\begin{array}{l}\text { Medium } \\
9(13.0 \%)\end{array}$} & \multirow{2}{*}{$\begin{array}{l}\text { Low } \\
6(10.3 \%)\end{array}$} & & & \\
\hline & Disagree & & & & & & \\
\hline COMPATIBLE & Neither agree nor disagree & $39(52.7 \%)$ & $38(55.1 \%)$ & $19(32.8 \%)$ & $96(47.8 \%)$ & & \\
\hline & Agree & $22(29.7 \%)$ & $22(31.9 \%)$ & $33(56.9 \%)$ & $77(38.3 \%)$ & & \\
\hline & Disagree & $5(6.8 \%)$ & $2(2.9 \%)$ & $2(3.4 \%)$ & $9(4.5 \%)$ & 12.206 & .016 \\
\hline COMPLEXITY & Neither agree nor disagree & $29(39.2 \%)$ & $11(15.9 \%)$ & $16(27.6 \%)$ & $56(27.9 \%)$ & & \\
\hline & Agree & $40(54.1 \%)$ & $56(81.2 \%)$ & $40(69.0 \%)$ & $136(67.7 \%)$ & & \\
\hline & Disagree & $14(18.9 \%)$ & $13(18.8 \%)$ & $8(13.8 \%)$ & $35(17.4 \%)$ & 15.177 & .004 \\
\hline RELIABILITY & Neither agree nor disagree & $37(50.0 \%)$ & $32(46.4 \%)$ & $14(24.1 \%)$ & $83(41.3 \%)$ & & \\
\hline & Agree & $23(31.1 \%)$ & $24(34.8 \%)$ & $36(62.1 \%)$ & $83(41.3 \%)$ & & \\
\hline & Disagree & $5(6.8 \%)$ & $3(4.3 \%)$ & $6(10.3 \%)$ & $14(7.0 \%)$ & 3.826 & .430 \\
\hline USEFULNESS & Neither agree nor disagree & $16(21.6 \%)$ & $9(13.0 \%)$ & $10(17.2 \%)$ & $35(17.4 \%)$ & & \\
\hline & Agree & $53(71.6 \%)$ & $57(82.6 \%)$ & $42(72.4 \%)$ & $152(75.6 \%)$ & & \\
\hline Total & & 74 & 69 & 58 & 201 & & \\
\hline
\end{tabular}

Source: Field Data (2019)

\subsection{Relationship Between Technological Features and HRIS Effectiveness}

This study used the user satisfaction approach to measure HRIS effectiveness in LGAs. The approach is based on the opinion of the user on the HRIS, which they use. Human Resource Officers (HROs) were asked about their level of agreement or disagreement with statements related with their satisfaction with HRIS in LGAs. These include; Compatibility-the system can be rapidly changed or upgraded, and the system can be legally accessed from other devices; Complexity-the system provides clear instructions for users to operate, prepare inputs, interpret outputs, and the procedures provided are clear and detailed; Reliability-HRIS has been reliably operated in your district; and Usefulness-the information addresses users' needs, and the system facilitates decision making.

\subsection{Relationship Between Technological Features and Information Timeliness}

\subsubsection{Up-to-Date Information}

The results in table 3 indicate that all technological features namely the system being rapidly changed or upgraded level $\chi^{2}$ $(d f)=11.985, \mathrm{p}<0.001)$, the system provides clear instructions for users to operate, prepare inputs, and interpret outputs level $\left.\chi^{2}(d f)=8.623, \mathrm{p}=0.003\right)$, the procedures provided are clear and detailed level $\left.\chi^{2}(d f)=4.862, \mathrm{p}=0.019\right)$, HRIS has been reliably operated in your district level $\chi^{2}(d f)=7.1154, \mathrm{p}$ $=0.006)$, the information addresses the needs of the users $\chi^{2}(d f)$ $=7.1154, \mathrm{p}=0.001)$ the system facilitates decision making level $\left.\chi^{2}(d f)=3.370, \mathrm{p}=0.046\right)$. These had a statistically significant association with current information status. Their $\mathrm{P}$-values are below our significance threshold of $\mathrm{P}<0.05$. However, the system being legally accessed from other devices $\left.\chi^{2}(d f)=0.428, \mathrm{p}=0.305\right)$ was found to have a statistically insignificant association with the status of the current information since its $\mathrm{p}$-value is above $0.05(\mathrm{P}>0.05)$.

\subsubsection{Information Captured Time}

Table 3 indicates that all technological features namely the procedures provided are clear and detailed $\left(\chi^{2}(d f)=13.493, \mathrm{p}\right.$ $<0.001)$, HRIS has been reliably operated in your district $\left(\chi^{2}\right.$ $(d f)=6.780, \mathrm{p}=0.007)$, the information addresses my needs $\chi^{2}$ $(d f)=13.659, \mathrm{p}<0.001)$, the system facilitates decision making $\left.\chi^{2}(d f)=4.372, \mathrm{p}=0.025\right)$ and the system is legally accessed $\chi^{2}(d f)=8.623, \mathrm{p}=0.003$ ) have a statistically significant association with time captured since their P-values are below our significance threshold of $p<0.05$. However, the system being rapidly changed or upgraded $\left(\chi^{2}(d f)=2.655, \mathrm{p}=\right.$ $0.070)$, the system provides clear instructions for users to operate, prepare inputs, and interpret outputs $\chi^{2}(d f)=1.750, \mathrm{p}$ $=0.120$ ) were found to have a statistically insignificant association with the time captured.

\subsubsection{Time Saving}

Table 3 indicates that all technological features namely the system provides clear instructions for users to operate, prepare inputs, and interpret outputs $\left(\chi^{2}(d f)=4.922, \mathrm{p}=0.019\right)$, the procedures provided are clear and detailed $\left(\chi^{2}(d f)=6.304, \mathrm{p}=\right.$ $0.009)$, the information addresses my needs $\left(\chi^{2}(d f)=18.055\right.$, $\mathrm{p}<0.001)$, were found to have a statistically significant 
association with time saving since their P-values are below our significance threshold of $\mathrm{P}<0.05$. However, the system being legally accessed from other devices $\left(\chi^{2}(d f)=2.452\right.$, $p=0.081)$, the system facilitates decision making $\left(\chi^{2}(d f)=\right.$ $0.14, p=0.511)$, and HRIS has been reliably operated in your district $\left(\chi^{2}(d f)=0.53, p=0.467\right)$ system being rapidly changed or upgraded $\left(\chi^{2}(d f)=0.503, \mathrm{p}=0.289\right)$, were found to have a statistically insignificant association with time saving.

\subsection{Relationship Between Technological Features and Information Completeness}

\subsubsection{Sufficiency of Information}

Table 4 shows that four technological features, namely the system being rapidly changed or upgraded $\left(\chi^{2}(d f)=7.390, p=\right.$ $0.005)$, the system provides clear instructions for users to operate $\left(\chi^{2}(d f)=7.479, p=0.005\right)$, the system facilitates decision making $\left(\chi^{2}(d f)=12.366, p<0.001\right)$, the system being legally accessed from other devices $\left(\chi^{2}(d f)=9.848, p=\right.$ 0.001 ), were found to have a statistically significant association with sufficiency of information since their $\mathrm{p}$-values are below our significance threshold of $\mathrm{p}<0.05$. However, the system prepares inputs and interprets outputs $\left(\chi^{2}\right.$ $(d f)=0.151, p=0.405)$, the procedures provided are clear and detailed $\left(\chi^{2}(d f)=0.641, p=0.258\right)$, HRIS has been reliably operated in your district $\left(\chi^{2}(d f)=0.816, p=0.225\right)$ were found to have a statistically insignificant association with the sufficiency of information.

\subsubsection{Complete Data Sets}

Table 4 presents the four technological features, namely the system being rapidly changed or upgraded $\left(\chi^{2}(d f)=7.390, p=\right.$ $0.005)$, the information addresses my needs $\left(\chi^{2}(d f)=7.479, p\right.$ $=0.005)$, the system being legally accessed from other devices $\left(\chi^{2}(d f)=12.366, p<0.001\right)$, the system facilitates decision making $\left(\chi^{2}(d f)=9.848, p=0.001\right)$. The technological features mentioned above had a statistically significant association with complete data sets since their p-values are below our significance threshold of $\mathrm{p}<0.05$. The rest, namely the system provides clear instructions for users to operate, prepare inputs and interpret outputs $\left(\chi^{2}(d f)=0.151, p=\right.$ $0.405)$, the procedures provided are clear and detailed $\left(\chi^{2}(d f)\right.$ $=0.641, p=0.258)$, HRIS has been reliably operated in your district $\left(\chi^{2}(d f)=0.816, p=0.225\right)$ were found to have a statistically insignificant association with complete data sets.

Table 3. Relationships between Technological Features and Information Timeliness.

\begin{tabular}{|c|c|c|c|c|}
\hline FEATURES & n\% & Current/Update Information $\left(\chi^{2}, p\right)$ & Information Captured Time $\left(\chi^{2}, p\right)$ & Time Saving $\left(\chi^{2}, p\right)$ \\
\hline System being changed/upgraded & & & & \\
\hline $\begin{array}{l}\text { Disagree } \\
\text { Agree } \\
\text { System is legally accessed }\end{array}$ & $\begin{array}{l}75(37) \\
126(63)\end{array}$ & $11.985,<0.001$ & $2.655,0.070$ & $0.503,0.289$ \\
\hline $\begin{array}{l}\text { Disagree } \\
\text { Agree } \\
\text { Provision of clear instruction }\end{array}$ & $\begin{array}{l}110(55) \\
91(45)\end{array}$ & $0.428,0.305$ & $8.623,0.003$ & $2.452,0.081$ \\
\hline $\begin{array}{l}\text { Disagree } \\
\text { Agree } \\
\text { Procedures are clear and detailed }\end{array}$ & $\begin{array}{l}110(55) \\
91(45)\end{array}$ & $8.623,0.003$ & $1.750,0.120$ & $4.922,0.019$ \\
\hline $\begin{array}{l}\text { Disagree } \\
\text { Agree }\end{array}$ & $\begin{array}{l}109(54) \\
92(46)\end{array}$ & $4.862,0.019$ & $13.493,<0.001$ & $6.304,0.009$ \\
\hline $\begin{array}{l}\text { HRIS reliably operated } \\
\text { Disagree } \\
\text { Agree }\end{array}$ & $\begin{array}{l}83(41) \\
118(59)\end{array}$ & $7.115,0.006$ & $6.780,0.007$ & $0.53,0.467$ \\
\hline Information addresses the need & & \multirow[b]{2}{*}{$7.1154,0.001$} & \multirow[b]{2}{*}{$13.659,<0.001$} & \multirow[b]{2}{*}{$18.055,<0.001$} \\
\hline $\begin{array}{l}\text { Disagree } \\
\text { Agree } \\
\text { HRIS facilitates decision making }\end{array}$ & $\begin{array}{l}128(64) \\
73(36)\end{array}$ & & & \\
\hline $\begin{array}{l}\text { Disagree } \\
\text { Agree }\end{array}$ & $\begin{array}{l}145(72) \\
56(28)\end{array}$ & $3.370,0.046$ & $4.372,0.025$ & $0.14,0.511$ \\
\hline
\end{tabular}

Source: Field Data (2019)

\subsection{Relationship Between Technological Features and Information Accuracy}

\subsubsection{Error-Free Information}

Table 5 indicates that two technological features, namely the system prepares inputs and interprets outputs $\left(\chi^{2}(d f)=\right.$ $8.130, \mathrm{p}=0.004)$, HRIS has been reliably operated in your district $\left(\chi^{2}(d f)=4.867, \mathrm{p}=0.019\right)$, had a statistically significant association with error-free information since their $\mathrm{P}$-values are below our significance threshold of $\mathrm{P}<0.05$. Some factors like the system being legally accessed from other devices $\left(\chi^{2}(d f)=0.647, \mathrm{p}=0.271\right)$, the procedures provided are clear and detailed $\left(\chi^{2}(d f)=0.618 \mathrm{p}=0.281\right)$, the system being rapidly changed or upgraded $\left(\chi^{2}(d f)=3.404, \mathrm{p}=\right.$ $0.051)$, the system provides clear instructions for users to 
operate the information addresses the needs $\left(\chi^{2}(d f)=0.001, \mathrm{p}\right.$ $=0.565)$, the system facilitates decision making $\left(\chi^{2}(d f)=\right.$ $2.272, \mathrm{p}=0.093)$, were found have a statistically insignificant association with the error-free information.

\subsubsection{Reliable of Information}

Table 5 indicates that six technological features, namely the system provides clear instructions for users to operate, prepare inputs and interpret outputs $\left(\chi^{2}(d f)=4.607, \mathrm{p}=0.022\right)$, the procedures provided are clear and detailed $\left(\chi^{2}(d f)=12.820, \mathrm{p}\right.$ $<0.001)$, HRIS has been reliably operated in your district $\left(\chi^{2}\right.$ $(d f)=18.247, \mathrm{p}<0.001)$, the information addresses my needs $\left(\chi^{2}(d f)=21.260, \mathrm{p}<0.001\right)$, the system being legally accessed from other devices $\left(\chi^{2}(d f)=16.958, \mathrm{p}<0.001\right)$, the system facilitates decision making $\left(\chi^{2}(d f)=5.985, \mathrm{p}=0.010\right)$, had a statistically significant association with reliable information since their $\mathrm{p}$-values are below our significance threshold of $\mathrm{P}<0.05$. However, the system being rapidly changed or upgraded $\left(\chi^{2}(d f)=17.781, \mathrm{p}=0.289\right)$ was found to have a statistically insignificant association with the reliable information.

\subsubsection{Reality of Information}

Table 5 indicates that out of nine technological features, five, namely the system being rapidly changed or upgraded $\chi^{2}$ $(d f)=9.315, \mathrm{p}=0.002)$, the procedures provided are clear and detailed $\left.\chi^{2}(d f)=5.143, \mathrm{p}=0.017\right)$, the system facilitates decision making $\left.\chi^{2}(d f)=5.635, \mathrm{p}=0.013\right)$, HRIS has been reliably operated in your district $\left.\chi^{2}(d f)=7.284, \mathrm{p}=0.005\right)$, the information addresses my needs $\left.\chi^{2}(d f)=14.409, \mathrm{p}<0.001\right)$

Technological features had a statistically significant association with reality of information since their $\mathrm{p}$-values are below our significance threshold of $p<0.05$. However, the system being legally accessed from other devices $\chi^{2}(d f)=$ $1.746, \mathrm{p}=0.120$ ), the system provides clear instructions for users to operate, prepare inputs, and interpret outputs $\chi^{2}(d f)=$ $0.000, p=0.555)$ were found to have a statistically insignificant association with the reality of information.

Table 4. Relationship between Technological Features and Information Completeness.

\begin{tabular}{|c|c|c|c|}
\hline Features & n\% & Sufficiency of Information ( $\chi^{2}, p$ value) & Complete Data Sets $\left(\chi^{2}, p\right.$ value $)$ \\
\hline $\begin{array}{l}\text { System being changed/upgraded } \\
\text { Disagree } \\
\text { Agree }\end{array}$ & $\begin{array}{l}75(37) \\
126(63)\end{array}$ & $7.390,0.005$ & $7.390,0.005$ \\
\hline $\begin{array}{l}\text { System is legally accessed } \\
\text { Disagree } \\
\text { Agree }\end{array}$ & $\begin{array}{l}110(55) \\
91(45)\end{array}$ & $9.848,0.001$ & $12.366,<0.001$ \\
\hline $\begin{array}{l}\text { Provision of clear instruction } \\
\text { Disagree } \\
\text { Agree } \\
\text { Procedures are clear and detailed }\end{array}$ & $\begin{array}{l}110(55) \\
91(45)\end{array}$ & $7.479,0.005$ & $0.151,0.405$ \\
\hline $\begin{array}{l}\text { Disagree } \\
\text { Agree } \\
\text { HRIS is reliably operated }\end{array}$ & $\begin{array}{l}109(54) \\
92(46)\end{array}$ & $0.641,0.258$ & $0.641,0.258$ \\
\hline $\begin{array}{l}\text { Disagree } \\
\text { Agree } \\
\text { Information address the need }\end{array}$ & $\begin{array}{l}83(41) \\
118(59)\end{array}$ & $0.816,0.225$ & $0.816,0.225$ \\
\hline $\begin{array}{l}\text { Disagree } \\
\text { Agree }\end{array}$ & $\begin{array}{l}128(64) \\
73(36)\end{array}$ & $0.151,0.405$ & $7.479,0.005$ \\
\hline $\begin{array}{l}\text { HRIS facilitate decision making } \\
\text { Disagree } \\
\text { Agree }\end{array}$ & $\begin{array}{l}145(72) \\
56(28)\end{array}$ & $12.366,<0.001$ & $9.848,0.001$ \\
\hline
\end{tabular}

Source: Field Data (2019)

Table 5. Relationship between Technological Features and Information Accuracy.

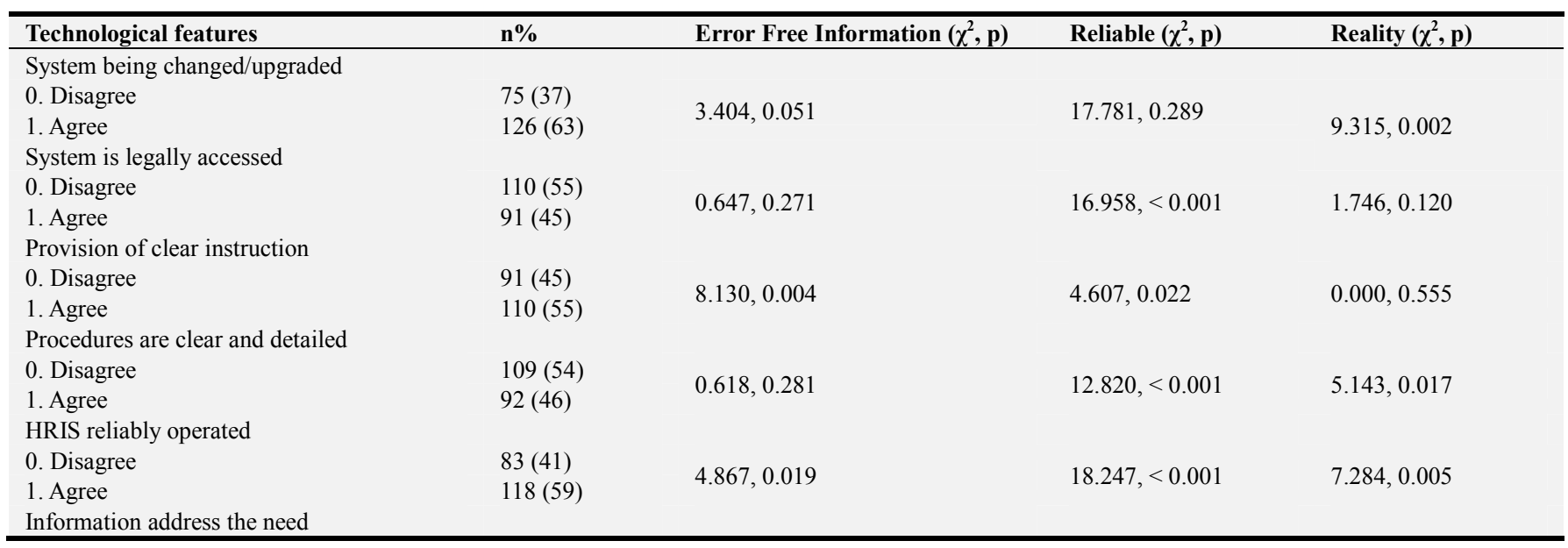




\begin{tabular}{|c|c|c|c|c|}
\hline Technological features & $\mathrm{n} \%$ & Error Free Information $\left(\chi^{2}, p\right)$ & Reliable $\left(\chi^{2}, \mathbf{p}\right)$ & Reality $\left(\chi^{2}, \mathbf{p}\right)$ \\
\hline $\begin{array}{l}0 . \text { Disagree } \\
\text { 1. Agree }\end{array}$ & $\begin{array}{l}128(64) \\
73(36)\end{array}$ & \multirow[t]{2}{*}{$0.001,0.565$} & \multirow[t]{2}{*}{$21.260,<0.001$} & \multirow[t]{2}{*}{$14.409,<0.001$} \\
\hline HRIS facilitates decision making & & & & \\
\hline $\begin{array}{l}0 . \text { Disagree } \\
\text { 1. Agree }\end{array}$ & $\begin{array}{l}145(72) \\
56(28)\end{array}$ & $2.272,0.093$ & $5.985,0.010$ & $5.635,0.013$ \\
\hline
\end{tabular}

Source: Field Data (2019)

\subsection{Influence of Technological Features on HRIS Effectiveness}

Based on model fitting information, data entered adequately fitted the models and at least one of the predicators is significantly related to the response variable. The results of Goodness-of-Fit show that two models (i.e. timeliness and completeness) do not fit well $(\mathrm{p}<0.05)$. The rest including accuracy have a large p-value, which suggests that the model fits the data very well. The results of Pseudo R-square Statistics (the pseudo $\mathrm{R}^{2}$ values) (i.e. Nagelkerke for timeliness $=0.250$, for completeness $=23.2 \%$ and accuracy $=$ 27.8 ) suggest that the model containing technological features was a poor predictor of the outcome.

Table 6. Parameter Estimates for Technological Features.

\begin{tabular}{|c|c|c|c|c|c|c|c|c|c|}
\hline & & & \multirow{2}{*}{ Estimate } & \multirow{2}{*}{ Std. Error } & \multirow{2}{*}{ Wald } & \multirow{2}{*}{ df } & \multirow{2}{*}{ Sig. } & \multicolumn{2}{|c|}{ 95\% Confidence Interval } \\
\hline & & & & & & & & Lower Bound & Upper Bound \\
\hline \multirow[t]{8}{*}{ Timeliness } & \multirow[t]{4}{*}{ Threshold } & [TIMELINESS = 1.00] & 1.033 & 1.289 & 0.641 & 1 & 0.423 & -1.495 & 3.56 \\
\hline & & [TIMELINESS = 2.00] & 4.704 & 1.004 & 21.965 & 1 & $<.001$ & 2.737 & 6.671 \\
\hline & & [TIMELINESS = 3.00] & 7.362 & 1.077 & 46.699 & 1 & $<.001$ & 5.25 & 9.473 \\
\hline & & [TIMELINESS = 4.00] & 9.977 & 1.177 & 71.808 & 1 & $<.001$ & 7.669 & 12.284 \\
\hline & \multirow[t]{4}{*}{ Location } & Compatibility & 0.571 & 0.183 & 9.776 & 1 & 0.002 & 0.213 & 0.93 \\
\hline & & Complexity & 0.791 & 0.212 & 13.878 & 1 & $<.001$ & 0.375 & 1.207 \\
\hline & & Reliability & 0.451 & 0.189 & 5.722 & 1 & 0.017 & 0.081 & 0.821 \\
\hline & & Usefulness & 0.187 & 0.213 & 0.771 & 1 & 0.380 & -0.23 & 0.604 \\
\hline \multirow[t]{8}{*}{ Completeness } & \multirow[t]{4}{*}{ Threshold } & [COMPLETENESS = 1.00] & 2.616 & 0.963 & 7.387 & 1 & 0.007 & 0.73 & 4.503 \\
\hline & & [COMPLETENESS = 2.00] & 5.965 & 1.021 & 34.153 & 1 & $<.001$ & 3.964 & 7.965 \\
\hline & & [COMPLETENESS = 3.00] & 7.165 & 1.051 & 46.435 & 1 & $<.001$ & 5.104 & 9.225 \\
\hline & & [COMPLETENESS = 4.00] & 9.273 & 1.119 & 68.675 & 1 & $<.001$ & 7.08 & 11.466 \\
\hline & \multirow[t]{4}{*}{ Location } & Compatibility & 0.458 & 0.175 & 6.877 & 1 & 0.009 & 0.116 & 0.801 \\
\hline & & Complexity & 0.306 & 0.201 & 2.324 & 1 & 0.127 & -0.088 & 0.7 \\
\hline & & Reliability & -0.157 & 0.18 & 0.762 & 1 & 0.383 & -0.509 & 0.195 \\
\hline & & Usefulness & 1.158 & 0.224 & 26.641 & 1 & $<.001$ & 0.719 & 1.598 \\
\hline \multirow[t]{8}{*}{ Accuracy } & \multirow[t]{4}{*}{ Threshold } & [ACCURACY $=1.00]$ & 1.431 & 1.326 & 1.164 & 1 & 0.281 & -1.168 & 4.029 \\
\hline & & {$[$ ACCURACY $=2.00]$} & 6.244 & 1.107 & 31.82 & 1 & $<.001$ & 4.075 & 8.414 \\
\hline & & {$[\mathrm{ACCURACY}=3.00]$} & 9.343 & 1.22 & 58.682 & 1 & $<.001$ & 6.952 & 11.733 \\
\hline & & {$[\mathrm{ACCURACY}=4.00]$} & 12.186 & 1.358 & 80.481 & 1 & $<.001$ & 9.524 & 14.848 \\
\hline & \multirow[t]{4}{*}{ Location } & Compatibility & 0.241 & 0.187 & 1.672 & 1 & 0.196 & -0.124 & 0.607 \\
\hline & & Complexity & 0.6 & 0.222 & 7.284 & 1 & 0.007 & 0.164 & 1.036 \\
\hline & & Reliability & 0.523 & 0.197 & 7.018 & 1 & 0.008 & 0.136 & 0.909 \\
\hline & & Usefulness & 0.803 & 0.231 & 12.072 & 1 & 0.001 & 0.35 & 1.256 \\
\hline
\end{tabular}

Source: Field Data (2019)

Table 6 presents parameter estimates, which give information on the influence of predictor variables. The Wald statistics were non-zero, which implied that there was interaction between the dependent and independent variables. The results imply that technological features influence HRIS effectiveness (i.e. Timeliness, Completeness, and Accuracy). Out of the 12 independent variables for the three models, eight variables were statistically significant and positively influenced HRIS effectiveness in LGAs. These are Compatibility, Complexity and Reliability for timeliness; compatibility and usefulness for completeness; and Complexity, Reliability and Usefulness for accuracy. However, the level of influence differs among technological features, which are shown to be statistically significant. This is indicated by the magnitude of $\beta$ coefficients and the level of significant (p-value). The most influential variables in descending order for every element of effectiveness are as follows: For completeness-usefulness $(\beta=1.158, p<0.001)$, and compatibility $(\beta=0.458, \quad \mathrm{p}=0.009)$; for timeliness-complexity $(\beta=0.791, p<0.001)$, compatibility $(\beta$ $=0.571, \mathrm{p}=0.002)$, and reliability $(\beta=0.451, \mathrm{p}=0.017)$; and for accuracy-complexity $(\beta=0.6, p=0.007)$, reliability $(\beta=$ $0.523, p=0.008)$, and usefulness $(\beta=0.803, p<0.001)$.

\section{Discussion}

\subsection{Distribution of Technological Features}

The results show a general distribution of technological features across regions with high, medium and low levels of HRIS challenges. The findings indicate that the majority of HROs who agreed that the system was compatible were from regions with low levels of HRIS challenges (i.e. in low 
category). Similarly, the same people, covering a majority of $62.1 \%$ agreed that the system was reliable. This was in respect to HROs from regions with a low number of challenges (i.e. in low category). The plausible explanation to why HROs in regions categorized as low observed that the system is compatible, reliable, and useful was the high level of ICT skills and commitment. ICT skills in HRIS usage was highly acknowledged [15, 16, 29, 37 39]. ICT skills enable the system user to be able to maintain, evaluate, and enhance the databases to avoid information leaks or losses. Thus, regions with HROs with ICT skills are better placed to use the system effectively.

\subsection{Relationship Between Technological Features and Effectiveness of HRIS}

The results in table 3 indicate that there is a strong relationship between timeliness (i.e. current information) and some technological features. These include: 1) the system can be changed or upgraded, 2) the system provides clear instructions for users to operate, prepare inputs, and interpret outputs, 3) the procedures provided are clear and detailed, 4) HRIS has been reliably operated in the district, 5) the information addresses the needs of the user, and 6) the system facilitates decision making. In addition, the results in table 3 show that timeliness (i.e. time captured) is strongly associated with: 1) the procedures provided are clear and detailed; 2) HRIS has been reliably operated in the district, 3) the information addresses the needs of the user, 4) the system facilitates decision making 5) the system is legally accessed from other devises. Furthermore, results in table 3 indicate a strong relationship between timeliness (i.e. time saving) and: 1) the system being rapidly changed or upgraded, 2) the system provides clear instructions for users to operate, 3) prepare inputs and interpret outputs, 4) the procedures provided are clear and detailed, 5) the information addresses needs of the users.

A closer look at the results shows that all elements of timeliness (i.e. current information, time captured, and time saving) have a strong relationship with only two technological features. These include: 1) the procedures provided are clear and detailed; 2) information addresses the needs of the user. The procedures provided are clear and detailed probably due to the presence of the Human Capital Management Information System (HCMIS) user manual. It was reported during interviews with Human Resource Officers (HROs) that the use of HRIS is guided by the manual, which was developed by the President's Office-Public Service Management (PO-PSM) in 2011 and revised in 2016 [17, 37].

The response that the information from the HRIS addresses needs of the users echoes the opinion of the HRO from PO-PSMGG who was asked how the use of HRIS enables LGAs to improve employees' information handling. He said:

Our system has helped us to keep all records of employees including their monthly salary details. The system has helped us to store information on age, education level, salary package and position of the employee although other information like performance appraisals and trainings are still being stored using the old system: this is because the new system doesn't accommodate such information.

When responding to the question on whether the objectives of introducing HRIS in LGAs have been achieved, he said:

The system has benefited us a lot especially in keeping us informed about our workers, where they are, their levels of education, to know about the available vacancies and who should be transferred and where to be transferred. The system has also kept us informed on many things on the workers including situations when the worker was warned over something.

Results in table 4 show the relationship between two elements of completeness and technological features. The results show that completeness (i.e. sufficiency of information) is strongly associated with: 1) the system being rapidly changed or upgraded, 2) the system provides clear instructions for users to operate, 3 ) the system facilitates decision making. The results in table 4 show that completeness (complete data sets) is strongly associated with 1) the system being rapidly changed or upgraded, and 2) the information addresses the needs. A closer look indicates that results in both tables imply that completeness is strongly associated with the system being rapidly changed or upgraded, the information addresses the needs of users and it facilitates decision making. This is because both appear to be statistically significant.

Explanation as to why the majority of respondents believed that the HRIS can rapidly be changed or upgraded had connections with the previous system, which was paper-based system. The manual system was characterized by slowness, inaccuracy, and incompleteness in the output [16]. The respondents admitted that through the use of the HRIS, the workload of the HROs have been reduced. It is now easier to update employee information and therefore avoid critical HRM challenges in the public sector, which were associated with the use of paper-based system. These include fraud in the public payroll, unqualified civil servants, delayed employee promotion, and poor employees training and development plans $[18,23,33]$.

Furthermore, the results show that the two technological features are strongly associated with accuracy (i.e. error free information) (see Table 5), while six are strongly associated with accuracy (i.e. reliable information) (see Table 5) and five are strongly associated with accuracy (i.e. reality) (see Table 5). However, only one technology characteristic, which is the HRIS, has been reliably operated in the district, is strongly correlated with all three elements of accuracy. As defined earlier, accuracy is the degree of absence of error in the process of generating information [36]. Therefore, the findings suggest that the challenge of internet connection, which was reported in previous studies to affect HRIS operations $[18,24]$ is now resolved.

\subsection{Influence of Technological Features on HRIS Effectiveness in LGAs}

Table 6 show results of three ordered logistic regression models that were carried out to assess the influence of technological features on three dimensions of effectiveness of 
HRIS: timeliness, completeness, and accuracy. Performance of all models is statistically significant ( $p$-values less than 0.05). The descriptive measure of goodness-of-fit also indicates that all three models fit the data well.

The results in table 6 show parameter estimates, which give the level and direction of influence of each independent variable and whether such influence is statistically significant. Direction can be either positive or negative and is indicated by (-) sign one none in $\beta$ coefficient in column labeled estimates. A positive sign associated with a $\beta$ coefficient shows that the particular technological characteristic increases the logit of the dependent variable. Out of 12 independent variables for three models, eight variables were statistically significant and positively influenced HRIS effectiveness in LGAs. These are compatibility, complexity and reliability for timeliness; compatibility and usefulness for completeness; and complexity, reliability and usefulness for accuracy.

However, the level of influence differs among technological features, which are shown to be statistically significant. This is indicated by the magnitude of $\beta$ coefficients and level of significant ( $p$ value). The most influential variables in descending order for every element of effectiveness are as follows: for completeness-usefulness $(\beta=1.158, \mathrm{p}<0.001)$, and compatibility $(\beta=0.458, \mathrm{p}=0.009)$; for timeliness-complexity $(\beta=0.791, p<0.001)$, compatibility $(\beta$ $=0.571, \mathrm{p}=0.002)$, and reliability $(\beta=0.451, \mathrm{p}=0.017)$; and for accuracy-complexity $(\beta=0.6, p=0.007)$, reliability $(\beta=$ $0.523, p=0.008)$, and usefulness $(\beta=0.803, p=0.001)$. The findings show how technological features play a great role in influencing HRIS effectiveness. Similar observations have been made by several scholars (e.g. $[2,6,15]$.

Acknowledging the influence of technological features, the HRO PO-PSMGG said that the government is planning to purchase a new system that will satisfy the current need. He said this during an interview where he stated that:

We expect to adopt a new system by next year. The reason for this is twofold. Firstly, we purchased a system that was not suitable for us so the government through its system specialists is devising a means of coming up with a system that best suits us. Since we adopted a new system that captured a lot of unnecessary information, this time we are well prepared to store relevant information on especially employees whose information is insufficient compared to new employees who already found the system in place.

Secondly, the current system is outdated since it doesn't have modern modules. The new system will certainly meet the requirements of the government.

\section{Conclusion}

The study revealed the relationship between effectiveness of HRIS and technological features and influence of technological features on HRIS effectiveness in LGAs in Tanzania. The study showed the presence of the technological features that associate with three dimensions of effectiveness at different levels. These include timeliness, completeness, and accuracy. Timeliness was found to be strongly correlated with all technological features. These include1) the system can be changed or upgraded, 2) the system provides clear instructions for users to operate, prepare inputs, and interpret outputs, 3) the procedures provided are clear and detailed, 4) HRIS has been reliably operated in the district, 5) information addresses the needs of the users, and 6) the system facilitates decision making. The study, therefore, concluded that all technological features are very important to achieve current and timely HRIS outputs.

The results also showed that completeness is strongly associated with the system being rapidly changed or upgraded, and the information addresses the needs of the users. Therefore, the system is more efficient compared to the previous system, which was paper-based. In addition, the fact that HRIS has been reliably operated in the district is strongly correlated with all three elements of the accuracy (i.e. error-free information, reliable information, and reality). It is therefore, concluded that the LGAs have managed to alleviate most of the challenges associated with the use of the HRIS that were reported previously.

Furthermore, technological features were regressed against HRIS effectiveness to understand influence. The study used ordered logistic model and the results have shown that the eight variables have positive coefficients. It can be concluded that most technological features increase the effectiveness of HRIS in terms of timeliness, completeness, and accuracy. The results further showed that eight technological features statistically influenced the effectiveness of HRIS. These include usefulness, compatibility, complexity and reliability. It is therefore, concluded that for the HRIS in LGAs to be effective, it should be rapidly changed or upgraded, easy to use, reliably operated, and that information should address the needs of HROs.

\section{Implications of the Findings}

On the basis of the findings and the conclusions drawn, the following are the implications: first, there is a need for LGAs to improve compatibility by adopting technology, which can be changed rapidly or upgraded. This can be achieved by installing a newer or better version. The second implication is that LGAs need to enhance relevance by ensuring that information from the system addresses the needs of HROs. Currently, the system is reported to be underutilized. It is mainly used to store records on new recruitments. HRIS stores various reports, which facilitate decision making, human resource planning, and positional advancement of employees. Besides these basic functions, the other functions are not being explored by HROs. This calls for a system that allows the user to generate information, which is vital for decision making processes.

\section{Acknowledgements}

This paper is part of a $\mathrm{PhD}$ thesis by the first author at Mzumbe University titled "Determinants of Human Resource Information System (HRIS) Effectiveness in Local 
Government Authorities in Tanzania." We acknowledge the academic and financial support received from Mzumbe University and Ruaha Catholic University respectively in pursuit of the study that enabled us write this article.

\section{References}

[1] Aggarwal, N., and Kapoor, M. (2012). Human resource information systems (HRIS)-Its role and importance in business competitiveness. GianJyoti E-Journal, 1 (2), 1-13.

[2] Ahmer, Z. (2013). Adoption of Human Resource Information Systems Innovation in Pakistani Organizations. Journal of Quality and Technology Management, Volume IX, Issue II, Pp 25-50.

[3] Akoyo, S. I. and Muathe S. M. A. (2017). Towards a Theoretical Model for Human Resource Management Information Systems, Government Policy and Organizational Performance: A Research Agenda. IOSR Journal of Business and Management (IOSR-JBM). Volume 19, Issue 1. pp 43-53.

[4] Akwei, I. (2017). Thousands of Tanzanian Civil Servants Sacked Over Fake Certificates. Africa news, April 28 $8^{\text {th }}, 2017$. Retrieved on May $11^{\text {th }} 2017$ from http://www. africanews. Com.

[5] Al-Dmour, R. H., and Zu'bi, M. F. (2014). Factors motivating and inhibiting the practice of HRIS in business organizations: An empirical analysis. International Business Research, 7 (7), 139.

[6] Al-Mobaideen, H., Allahawiah, S. and Basio, E. (2013). Factors Influencing the Successful Adoption of Human Resource Information System: The Content of Aqaba Special Economic Zone Authority. Intelligent Information Management, 5, 1-9.

[7] Amrouni, K., and Arshah, R. (2018). Using UTAUT model to determine the Factors Affecting the Technology Acceptance in Judicial System Environment. Journal of Advanced Research in Computing and Application Vol 11, no 1 pp 17-22.

[8] Basbas S, TetouV and Politis I (2013). Ordinal and Binary Logistics Models for Examination of Behavioral, Infrastructure and Perception Factors Influencing Biking. Conference paper.

[9] Bhuiyan, M. B. U., and Rahman R (2014). Application of Human Resource Information System in the Firms of Bangladesh and its Strategic Importance. World Wide Research Vol 4 Issue 3.

[10] Davis, F. D. (1989). Perceived usefulness, perceived ease of use, and user acceptance of information technology, MIS Quarterly, 13 (3), 319-339.

[11] Elamir E and SadeqH (2010). Ordinal Regression to Analyze Employees Attitude Towards the Application of Total Quality Management. Journal of Applied Quantitative Methods, Vol 5 no 4.

[12] Gupta B. (2013). Human Resources Information System HRIS. Important Element of Current Scenario. Journal of Business and Management Vol 13, Issue 6 pp 41-46.

[13] Hendrickson, A. (2004). Human resource information systems: backbone technology of contemporary human resources. Journal of Labour Research, 24 (3), 381-394. Journal of
Studies in Social Sciences.

[14] Hickman, G. R., and Lee, D. S. (2001). Managing human resources in the public sector: a shared responsibility. Harcourt Brace.

[15] Hien, L. T., Nguyen, T. L. and Cuong, P. H. (2014). Key Determinants of Information System Effectiveness-An Empirical Case in Lac Hong University. International Journal of Information Technology and Business Management, Vol. 32 No. 1.

[16] Ishijima H, Mapunda M., Mndeme., Sukums S., Mlay, VS. (2015). Challenges and opportunities for effective adoption of HRH information systems in developing countries: National rollout of HRHIS and TIIS in Tanzania. Human Resources Health. 2015; 13 (48).

[17] Jahan, S. (2014) Human Resources Information System (HRIS): A Theoretical Perspective. Journal of Human Resource and Sustainability Studies, 2, 33-39.

[18] Jorojick D. P. (2015). The Influence of Human Resource Information System on Decision Making in LGAs: The Case of Lawson Version 9 in Kiteto District, Tanzania. A Dissertation Submitted in Partial/Fulfillment of the Requirements for Award of the Degree of Master of Science in Human Resource Management (MSc HRM) of Mzumbe University.

[19] Kassam, A. (2013). Challenges of Human Capital Management Information System (Lawson Version, 9) in Local Government Authorities: The case of Shinyanga Municipal Council. A Dissertation for Award of MSc Degree at Mzumbe University, Morogoro, Tanzania. 100pp.

[20] Kassim, N., Ramayah, T. and Kurnia, S. (2012). Antecedents and outcomes of human resource information system (HRIS) use. International Journal of Productivity and Performance Management, 61 (6), 603-623.

[21] Keegan, A., Huemann, M., \& Turner, J. R. (2012). Beyond the line: exploring the HRM responsibilities of line managers, project managers and the HRM department in four project-oriented companies in the Netherlands, Austria, the UK and the USA. The International Journal of Human Resource Management, 23 (15), 3085-3104.

[22] Kroenke, D. M. (2014). MIS Essentials (4th Ed.). Upper Saddle River, NJ: Pearson.

[23] Lameck, W. U. (2015). Explaining the Performance of Decentralized Recruitment in Tanzania Local Government Authorities on Institutional Context Perspective. International Journal of Academic Research in Business and Social Sciences Dec 2015, Vol. 5, No. 12.

[24] Lema, L. E. (2013). The Impact of Human Resources Information System in the Performance of Banking Industry: The Case Study of National Microfinance Bank Tanzania Ltd. Dissertation Submitted in Partial Fulfillment of Requirements for the Award of the Degree of Masters of Science in Human Resources Management of Mzumbe University.

[25] Materu, B. (2017). Tanzania Fake Workers Ordered to Leave by May 15. The East African, April $29^{\text {th }}, 2017$. Retrieved on May $11^{\text {th }} 2017$ from http://www.the eastafrican.co.ke.

[26] Matimbwa H and Masue O S. (2019). Usage and Challenges of Human Resources Information System in Tanzanian Public Organizations. Journal of Human Resource Management Vol 7, No 4, pp 131-137. 
[27] Mohammad H, Torabi S and DoganiA (2015) Application of Ordered Logit Model in Investigating the Factors Affecting Peoples Income A case of Tehran City. International Journal of Academic Research in Economics and Management Sciences Vol. 5, No. 3.

[28] Mustafa, M. M. (2009). Local government in Tanzania: does the local government law in Tanzania give autonomy to local government (Doctoral dissertation).

[29] Njau, N. F. (2018). Factors influencing adoption of human resource information system in Parastatal organizations; case of Dar es Salaam. A Dissertation for Award of MSc Degree at Dodoma University, Dodoma, Tanzania.

[30] Njau, S. (2017). Challenges in the Use of Human Capital management Information System (HCMIS) in Local Government Authorities. A Dissertation for Award of MSc Degree at Mzumbe University, Morogoro, Tanzania.

[31] Noe, R. A., Hollenbeck, J. R., Gerhart, B., \& Wright, P. M. (2015). Human resource management. Gaining a Competitive.

[32] Pallant, J. (2005). SPSS Survival Manual: A step by step guide to data analysis using SPSS for Windows (Version 12). Crows Nest, NSW: Allen \& Unwin.

[33] Sawe, D. and Maimu, D. (2001). International experience with civil service censuses and civil service databases. A case study 3-Tanzania. In McCallum, N., \& Tyler, V. (2001). London: International Records Management Trust.

[34] Singh, H. P, Jindal, S. and Samim, S. A. (2011). Role of Human
Resource Information System in Banking Industry of Developing Countries. Paper presented in The First International Conference on Interdisciplinary Research and Development, 31 May-1 June 2011, Thailand.

[35] Tagoe, M. (2012). Students' perception on incorporating E-learning into teaching and learning at University of Ghana. International Journal of Education and Development using Information and Communication Technology Vol 8, Issue 1, pp 91-103.

[36] Troshani, I., Jerram, C. and Hill, S. R., (2011). Exploring the public sector adoption of HRIS. Industrial Management \& Data Systems, 111 (3), 470-488.

[37] United Republic of Tanzania (URT). (2016a). Human Capital Management Information System (HCMIS) User Manual (2016). President's Office, Public Service Management. Government printer, Dar es Salaam.

[38] Venkatesh Y., M. G. Morris, G. B. Davis and Davis F. D. (2003). "User acceptance of information technology: toward a unified view". MIS Quarterly Vol. 27 (3), 425-78.

[39] World Bank (2002). Evidence-Based Governance in the Electronic Age. Case Study Personnel and Payroll Records and Information Systems in Tanzania. A World Bank/International Records Management Trust Partnership Project.

[40] Iaccino, L. (2017. Tanzania Fires 10000 Civil Servants Over Fake Qualifications. Newsweek, April 28 ${ }^{\text {th }}$, 2017. Retrieved on May $11^{\text {th }} 2017$ from http://www.newsweek.com. 